\title{
Microhardness, microstructure and electrical properties of ZVM ceramics
}

\author{
Abdel-Mageed H. KHAFAGY ${ }^{a}$, Sanaa M. EL-RABAIE ${ }^{b}$, Mohamed T. DAWOUD ${ }^{b, *}$, \\ M. T. ATTIA ${ }^{b}$ \\ ${ }^{a}$ Physics Department, Faculty of Science, Menufiya University, Shebin El-Koom 32511, Egypt \\ ${ }^{b}$ Physics and Engineering Mathematics Department, Faculty of Electronic Engineering, Menufiya University, \\ Menouf 32952, Egypt
}

Received: May 28, 2014; Revised: June 26, 2014; Accepted: July 06, 2014

(OThe Author(s) 2014. This article is published with open access at Springerlink.com

\begin{abstract}
The effect of $\mathrm{Mn}_{3} \mathrm{O}_{4}$ addition on microhardness, microstructure and electrical properties of vanadium oxide doped zinc oxide varistor ceramics is systematically investigated. The Vicker's microhardness $H_{\mathrm{V}}$ has decreased with increasing the amount of $\mathrm{Mn}_{3} \mathrm{O}_{4}$. Also, the average grain size has decreased from $27.51 \mu \mathrm{m}$ to $19.55 \mu \mathrm{m}$ with increasing the amount of $\mathrm{Mn}_{3} \mathrm{O}_{4}$ up to $0.50 \mathrm{~mol} \%$, whereas an increase in $\mathrm{Mn}_{3} \mathrm{O}_{4}$ up to $0.75 \mathrm{~mol} \%$ has caused the average grain size to increase and then it decreases with increasing $\mathrm{Mn}_{3} \mathrm{O}_{4}$ from $0.75 \mathrm{~mol} \%$ to $1.00 \mathrm{~mol} \%$. The sintered density has decreased from $5.38 \mathrm{~g} / \mathrm{cm}^{3}$ to $5.31 \mathrm{~g} / \mathrm{cm}^{3}$ with increasing the amount of $\mathrm{Mn}_{3} \mathrm{O}_{4}$. The varistor ceramic modified with $0.50 \mathrm{~mol} \% \mathrm{Mn}_{3} \mathrm{O}_{4}$ has exhibited excellent nonlinear properties, with 16.29 for the nonlinear coefficient and $441.9 \mu \mathrm{A} / \mathrm{cm}^{2}$ for the leakage current density. Furthermore, the sample doped with $0.50 \mathrm{~mol} \% \mathrm{Mn}_{3} \mathrm{O}_{4}$ has been found to possess donor density as $0.77 \times 10^{18} \mathrm{~cm}^{-3}$ and $0.916 \mathrm{eV}$ barrier height.
\end{abstract}

Keywords: ceramics; electrical properties; microstructure; varistor; $\mathrm{Mn}_{3} \mathrm{O}_{4}$ doped $\mathrm{ZnO}-\mathrm{V}_{2} \mathrm{O}_{5}$ varistor

\section{Introduction}

$\mathrm{ZnO}$ based varistors are semiconducting ceramic devices exhibiting nonlinear symmetrical currentvoltage $(I-V)$ or current density-electric field $(J-E)$ characteristics for both voltage polarities [1]. This is due to the presence of inter-granular layers with high resistance between $\mathrm{ZnO}$ grains having low resistance and Schottky barrier arising due to the surface states caused by the dopants. Such behaviors enable them to absorb large amount of energy. Consequently, they

\footnotetext{
* Corresponding author.

E-mail: dawoud.mohamed73@yahoo.com
}

have been extensively used for protecting electronic circuits, against voltage surges and for the voltage stabilization of electrical power lines.

The $I-V$ characteristic relation is expressed as [1]:

$$
I=K V^{\alpha}
$$

where $K$ is a constant and $\alpha$ is the nonlinear coefficient related to the material's microstructure. Besides the above coefficient, there are two other parameters, the breakdown voltage $V_{\mathrm{B}}$ and the leakage current $I_{\mathrm{L}}$. The breakdown voltage is calculated by the simple equation $[2,3]$ :

$$
V_{\mathrm{B}}=N_{\mathrm{gb}} \times V_{\mathrm{gb}}=(t / D) V_{\mathrm{gb}}
$$

where $N_{\mathrm{gb}}$ is the number of grain boundaries across the varistor's thickness $t ; D$ is the average grain size; and 
$V_{\mathrm{gb}}$ is the average voltage per grain boundary $(\approx 3 \mathrm{~V})$.

Also, in terms of the current density $J$ and the applied electric field $E$, the above $I-V$ relation is rewritten as

$$
J=(E / C)^{\alpha}
$$

where $C$ is a constant. Then the breakdown field $E_{\mathrm{B}}=$ $V_{\mathrm{gb}} / D$ [3] is usually taken as the field applied when the current flowing through the varistor is $1 \mathrm{~mA}$ [4]. Since the grain boundary barriers in the $\mathrm{ZnO}$ based varistors are of Schottky type, the current density $J$ in the first ohmic region of varistor characteristics is related to the electric field $E$ at a given absolute temperature $T$ by the equation $[5,6]$ :

$$
J=A T^{2} \exp \left[\left(\beta E^{1 / 2}-\varphi_{\mathrm{B}}\right) /(k T)\right]
$$

where $A=4 \rho e m k^{2} / h^{3}$ is the Richardson's constant; $\rho$ is the varistor density; $e$ is the electron charge; $m$ is the electron mass; $k$ is the Boltzmann constant; $h$ is the Plank's constant; $\beta$ is a constant related to the grain number per unit length and the barrier width $\omega$; and $\varphi_{\mathrm{B}}$ is the Schottky barrier height formed on the grain surfaces and arises due to the surface states caused by the dopants. Therefore, the electrical conductivity $\sigma$ of $\mathrm{ZnO}$ varistors could be calculated from the slopes of the $J-E$ curves in the first and third ohmic regions, while in the second nonlinear region where the current strongly increases due to the decrease of $\varphi_{\mathrm{B}}$, the conductivity is given by [7]:

$$
\sigma_{2}=\sigma_{1} \exp \left[(\alpha-1)\left(E_{2}-E_{1}\right) / E_{2}\right]
$$

where $\sigma_{1}$ is the conductivity corresponding to the first ohmic region; $\sigma_{2}$ is the conductivity of the second region; and $E_{1}$ and $E_{2}$ are two values on the linear part of the breakdown region.

The effects of doping $\mathrm{ZnO}$ based ceramics with few mole percentages of different oxides of some metals, e.g., $\mathrm{Bi}, \mathrm{Sb}, \mathrm{Co}, \mathrm{Mn}, \mathrm{Ni}, \mathrm{Cr}, \mathrm{Al}$ and $\mathrm{Fe}$, have been investigated by several authors [8-16]. Reported results of those studies show that the important physical properties mentioned above are closely related to the compositions and microstructures, i.e., they are dependent on density, grain size, morphology, distribution of any secondary phases and porosity. Therefore, by controlling these parameters, the nonlinear coefficient and breakdown field values could be improved in order to obtain the required electrical performance. Also, each of the above dopants plays a distinctive role in the subtle tuning of the final nonlinear characteristics of the varistor ceramics, while the overall electrical characteristics are resulted from the collective effect of all the microstructural features.

Multilayer chip ceramic products require that the inner-electrode materials should have their melting points (MP) relatively higher than the sintering temperature of their components [17-19]. Therefore, new ceramics are developed where a silver inner-electrode $\left(\mathrm{MP}=961{ }^{\circ} \mathrm{C}\right)$ can be used for making multilayer components which have their sintering temperatures around $900{ }^{\circ} \mathrm{C}$. Among those products, the binary system $\mathrm{ZnO}-\mathrm{V}_{2} \mathrm{O}_{5}$ has become a good candidate [17,20-24], since it can be sintered at a temperature in the vicinity of about $900{ }^{\circ} \mathrm{C}$ which is important for multilayer chip applications due to its ease of co-firing (sintering) with silver inner-electrode without using expensive palladium or platinum metals as electrode materials. However, effects of adding some different metal oxides and rare earths to the binary system $\mathrm{ZnO}-\mathrm{V}_{2} \mathrm{O}_{5}$ on the electrical properties have been investigated by several authors, e.g., $\mathrm{Mn}$ ions [25], $\mathrm{Mn}_{3} \mathrm{O}_{4}$ and $\mathrm{Nb}_{2} \mathrm{O}_{5}$ [26], $\mathrm{Mn}_{3} \mathrm{O}_{4}$ and $\mathrm{Er}_{2} \mathrm{O}_{3}$ [27], $\mathrm{MnO}_{2}-\mathrm{Er}_{2} \mathrm{O}_{3}$ and $\mathrm{Nb}_{2} \mathrm{O}_{5}$ [28,29], $\mathrm{MnO}_{2}-\mathrm{Nb}_{2} \mathrm{O}_{5}$ and $\mathrm{Bi}_{2} \mathrm{O}_{3}$ [30], and $\mathrm{MnO}_{2}$ [31,32]. The reported results of these works are dealt with the effects of different doping or the effects of sintering temperature on the microstructure, nonlinear and conduction behaviors of tested ceramics.

The present work is aimed to investigate and throw more lights on the microstructure and electrical properties of $x \mathrm{Mn}_{3} \mathrm{O}_{4}-0.5 \mathrm{~V}_{2} \mathrm{O}_{5}-(99.5-x) \mathrm{ZnO}(\mathrm{ZVM})$ ceramics, where $x=0,0.15,0.30,0.50,0.75$ and $1.00 \mathrm{~mol} \%$, as prepared by the conventional ceramic method and sintered at $900{ }^{\circ} \mathrm{C}$ for $5 \mathrm{~h}$. Besides, X-ray diffraction, scanning electron microscopy and energy dispersive X-ray analyses have been used to characterize the prepared ceramics.

\section{Experimental}

Reagent-grade raw materials of $\mathrm{ZnO}, \mathrm{V}_{2} \mathrm{O}_{5}$ and $\mathrm{Mn}_{3} \mathrm{O}_{4}$ were used for preparing $\mathrm{ZnO}$ based ceramics by solid state reaction technique according to the formula $x \mathrm{Mn}_{3} \mathrm{O}_{4}-0.5 \mathrm{~V}_{2} \mathrm{O}_{5}-(99.5-x) \mathrm{ZnO}$, where $x=0,0.15$, $0.30,0.50,0.75$ and $1.00 \mathrm{~mol} \%$. Weighed raw materials were mixed by ball-milling in exist of acetone for $28 \mathrm{~h}$. The mixture was dried at $120{ }^{\circ} \mathrm{C}$ for $12 \mathrm{~h}$. The dried mixture was milled using an agate mortar and after $0.8 \mathrm{wt} \%$ polyvinyl alcohol binder addition for $3 \mathrm{~h}$. The powder was uniaxially pressed into discs of $12 \mathrm{~mm}$ in diameter and $1.5 \mathrm{~mm}$ in thickness at a pressure of 9500 psi. The discs were put 
in porcelain crucible and sintered at $900{ }^{\circ} \mathrm{C}$ in air for $5 \mathrm{~h}$, and then the furnace was cooled to room temperature. The sintered samples were lapped and polished to $1.0 \mathrm{~mm}$ thickness. Silver paste was coated on both surfaces of the samples, and the ohmic contacts were formed by heating at $300{ }^{\circ} \mathrm{C}$ for $5 \mathrm{~min}$.

At first, both the sintered density and the Vicker's microhardness $H_{\mathrm{V}}$ were measured at room temperature $27{ }^{\circ} \mathrm{C}$. The density $\rho$ was determined by the Archimedes method with toluene as immersing liquid, while $H_{\mathrm{V}}$ was found by using a microhardness tester (HMV-2, Ver. 1.28, Shimatzu, Japan) where each sample was loaded at force equal to $4.902 \mathrm{~N}$ for $30 \mathrm{~s}$ and then $H_{\mathrm{V}}$ was estimated according to the relation $H_{\mathrm{V}}=0.1891 P / d^{2}$, where $P$ is the load applied and $d$ is the diagonal length of indenter impression.

The current density-electric field $(J-E)$ characteristics of the samples were recorded at room temperature. An electric circuit composed from a 500 V DC Gelman power supply (Model: 38207 ANN ARBOR, MICH., USA 48106), a digital multi-meter (GW Digital Multimeter Model: GDM-8034) and an auto ranging microvolt (Model: 197A DMM-Keithley) was used to measure the current passing through and voltage across the sample. The breakdown field $\left(E_{\mathrm{B}}\right)$ was measured at a current density of $1.0 \mathrm{~mA} / \mathrm{cm}^{2}$, and the leakage current density $\left(J_{\mathrm{L}}\right)$ was measured at $0.80 E_{\mathrm{B}}$. In addition, the non-ohmic coefficient $(\alpha)$ was determined from the current-voltage curve plotted on a $\log -\log$ scale, from which the slope of the curve gives the value $\alpha$ [8].

Also, for doing microstructure investigations, both surfaces of the samples were lapped and ground with $\mathrm{SiC}$ paper and polished with $0.3 \mu \mathrm{m} \mathrm{Al}_{2} \mathrm{O}_{3}$ powder to mirror-like surfaces. The polished samples were chemically etched using $1 \mathrm{HCl}: 1000 \mathrm{H}_{2} \mathrm{O}$ for $40 \mathrm{~s}$ and then coated with gold. The surface microstructure was then examined by a scanning electron microscope (SEM, JEOL, JSM5410, Japan). The average grain size $(D)$ was determined by the linear intercept method using the expression $D=1.56 L /(M N)$ [33], where $L$ is the random line length on the micrograph; $M$ is the magnification of the micrograph; and $N$ is the number of the grain boundaries intercepted by lines. The compositional elemental analysis of the selected areas on micrographs was determined by an attached energy dispersive X-ray analysis (EDX) system. The crystalline phases were identified by powder X-ray diffraction (XRD, X'pert-PRO MPD, Analytical,
Almelo, the Netherlands) with $\mathrm{Cu} \mathrm{K} \alpha$ radiation.

\section{Results and discussion}

\section{1 Microstructure investigations}

\subsubsection{Density and microhardness}

Figure 1 shows the compositional dependences of both the sintered density $\rho$ and the Vicker's microhardness $H_{\mathrm{V}}$ of $x \mathrm{Mn}_{3} \mathrm{O}_{4}-0.5 \mathrm{~V}_{2} \mathrm{O}_{5}-(99.5-x) \mathrm{ZnO}$ ceramics sintered at $900{ }^{\circ} \mathrm{C}$ for $5 \mathrm{~h}$, where $x$ changes from 0 to $1.00 \mathrm{~mol} \%$. This figure reveals that $\rho$ and $H_{\mathrm{V}}$ are rapidly decreased with increasing the $\mathrm{Mn}_{3} \mathrm{O}_{4}$ content up to $0.15 \mathrm{~mol} \%$. Then, the density continues its decreasing up to $0.50 \mathrm{~mol} \%$ of $\mathrm{Mn}_{3} \mathrm{O}_{4}$, while beyond this content it decreases slowly with the gradual increase of $\mathrm{Mn}_{3} \mathrm{O}_{4}$ up to $1.00 \mathrm{~mol} \%$. $H_{\mathrm{V}}$ has also slowly decreased as $x$ increases from $0.15 \mathrm{~mol} \%$ to $1.00 \mathrm{~mol} \%$, the end of tested range. Typical average results for both $\rho$ and $H_{\mathrm{V}}$ are listed in Table 1. The obtained values for $\rho$ in Table 1 are comparable with those reported for the same materials [17]. The above dependences of both $\rho$ and $H_{\mathrm{V}}$ on the mole percentage of $\mathrm{Mn}_{3} \mathrm{O}_{4}$ content can be interpreted as follows. Although gradual replacement of $\mathrm{ZnO}$ (molecular weight 81.369 ) by the same amount of $\mathrm{Mn}_{3} \mathrm{O}_{4}$ (molecular weight 228.812) in the $\mathrm{ZnO}$ based varistor matrix is supposed to increase the molecular weight of prepared samples, the bulk density is decreased all over the tested range as seen in Fig. 1. Also, it is

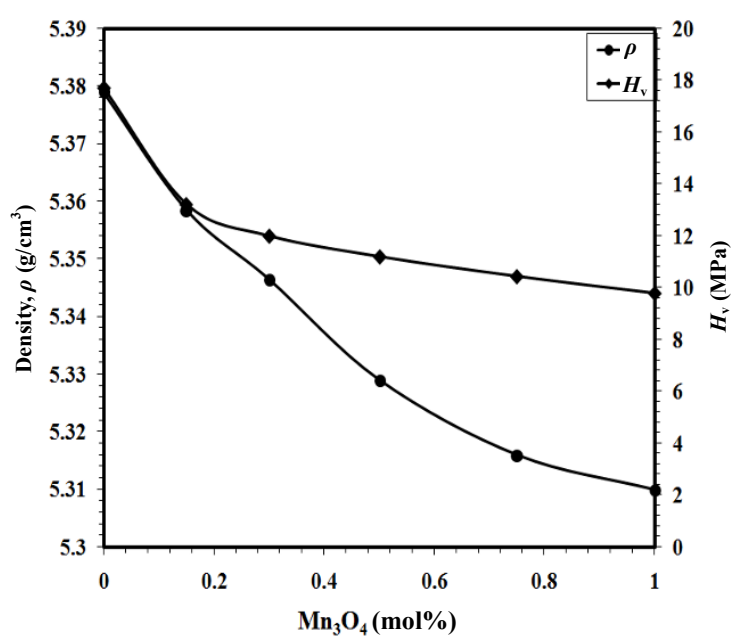

Fig. 1 Compositional dependences of the sintered density $\rho$ and the Vicker's microhardness $H_{\mathrm{V}}$ of $x \mathrm{Mn}_{3} \mathrm{O}_{4}-0.5 \mathrm{~V}_{2} \mathrm{O}_{5}-(99.5-x) \mathrm{ZnO}$ ceramics sintered at $900{ }^{\circ} \mathrm{C}$ for $5 \mathrm{~h}$, where $x$ changes from 0 to $1.00 \mathrm{~mol} \%$. 
Table 1 Average calculated values of density $\rho$, Vicker's microhardness $H_{\mathrm{V}}$, molar volume $V$ and grain size $D$ as found from both XRD and SEM results

\begin{tabular}{|c|c|c|c|c|c|}
\hline$x(\mathrm{~mol} \%)$ & $\left(\mathrm{g} / \mathrm{cm}^{3}\right)$ & $H_{\mathrm{V}}(\mathrm{MPa})$ & $\begin{array}{c}\text { Molar } \\
\text { volume } \\
V\left(\mathrm{~cm}^{3} / \mathrm{mol}\right)\end{array}$ & $\begin{array}{c}\text { Average } \\
\text { grain siz } \\
\text { (XRD) } L \\
(\mathrm{~nm})\end{array}$ & $\begin{array}{l}\text { Average } \\
\text { grain size } \\
\text { (SEM) } D \\
(\mu \mathrm{m})\end{array}$ \\
\hline 0.00 & 5.379 & 17.726 & 15.224 & 34.502 & 27.513 \\
\hline 0.15 & 5.359 & 13.209 & 15.324 & 31.110 & 21.303 \\
\hline 0.30 & 5.347 & 12.456 & 15.399 & 29.002 & 20.458 \\
\hline 0.50 & 5.329 & 11.212 & 15.506 & 27.211 & 19.545 \\
\hline 0.75 & 5.316 & 10.440 & 15.613 & 34.129 & 24.982 \\
\hline 1.00 & 5.310 & 9.799 & 15.700 & 30.510 & 23.670 \\
\hline
\end{tabular}

known that the density equals the molecular weight divided by the molar volume. This volume which increases due to the weak connectivity of the ceramic structure results in a decrease in microhardness of the varistor ceramics with increasing the $\mathrm{Mn}_{3} \mathrm{O}_{4}$ content (Table 1) in addition to the formation of some pores in the $\mathrm{ZnO}$ polycrystalline grains of varistor matrix by sintering at high temperature $900{ }^{\circ} \mathrm{C}$ (as will be seen in the SEM micrographs in Fig. 3). Thus, the observed decrease in density could be attributed analogously to an increase in the molar volume and the obtained decrease in microhardness due to the weakness of the structural connectivity and coupling between the $\mathrm{ZnO}$ grains [13]. On the other hand, it has been assumed that the decrease of sintered density is attributed to the volatility of $\mathrm{V}$ species for $\mathrm{V}_{2} \mathrm{O}_{5}$ with low melting point $690{ }^{\circ} \mathrm{C}[28]$.

\subsubsection{XRD analysis}

Figure 2 shows the dependence of XRD patterns of tested varistors on the mole percentage of $\mathrm{Mn}_{3} \mathrm{O}_{4}$ content. As indicated in Fig. 2, the observed diffraction graphs for all tested samples confirm the presence of the wurtzite hexagonal structure of the main $\mathrm{ZnO}$ primary phase. All diffraction peaks corresponding to this phase are indexed according to their reflection planes of polycrystalline Miler orientations (100), (002) and (101) $[7,13,34]$ as indicated in Fig. 2 with (101) index having the high-intensity major peak. Besides, there are some secondary phases, such as $\mathrm{Zn}_{3}\left(\mathrm{VO}_{4}\right)_{2}$ appeared as a result of the presence of $\mathrm{ZnO}-\mathrm{V}_{2} \mathrm{O}_{5}$ which acts as a liquid phase sintering aid for the formation of it [17,27-30] and Mn-rich $\mathrm{Mn}_{3} \mathrm{O}_{4}$ (for samples with $x=0.75 \mathrm{~mol} \%$ and $x=1.00 \mathrm{~mol} \%$ ) $[25,30]$. The average crystallite size $D$ is calculated in terms of X-ray line broadening at full width half maximum (FWHM) by using Scherer's equation $[7,13,24]$ for all tested samples and the average values are summarized in Table 1.

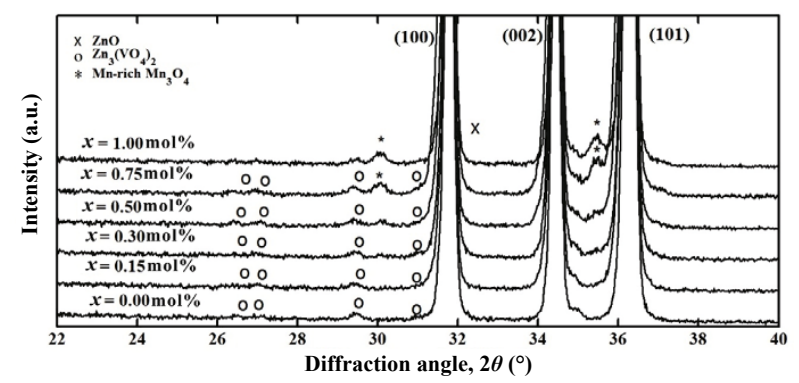

Fig. 2 Dependence of XRD patterns of tested ceramic varistors on the mole percentage of $\mathrm{Mn}_{3} \mathrm{O}_{4}$ content.

\subsubsection{SEM and EDX analyses}

Figure 3 shows the SEM micrographs of the samples with different amounts of $\mathrm{Mn}_{3} \mathrm{O}_{4}$ ( $x$ from 0 to $1.00 \mathrm{~mol} \%$ ). Inspection of this figure reveals the occurrence of $\mathrm{ZnO}$ major phase of large grains, and other different minor phases with small grains disperse randomly in the former major one such as $\mathrm{Zn}_{3}\left(\mathrm{VO}_{4}\right)_{2}$ and $\mathrm{Mn}$-rich $\mathrm{Mn}_{3} \mathrm{O}_{4}$ in addition to some pores (black regions), in agreement with Refs. [17,20] and the above XRD results (Fig. 2). Observed grains are of different sizes and are randomly distributed throughout the samples. The average value of grain size $D$ of observed grains was calculated for all specimens according to the equation [33], and the typical average values are listed in Table1. This table indicates that the values of $D$, even found from either XRD or SEM, have similarly changed with the gradual doping of $\mathrm{Mn}_{3} \mathrm{O}_{4}$, in which $D$ values decrease from $34.502 \mathrm{~nm}$ to $27.211 \mathrm{~nm}$ (XRD) and from $27.513 \mu \mathrm{m}$ to $19.545 \mu \mathrm{m}$ (SEM) with increasing the content of $\mathrm{Mn}_{3} \mathrm{O}_{4}$ from 0 up to $0.50 \mathrm{~mol} \%$. Then they increase up to $34.129 \mathrm{~nm}$ (XRD) and $24.982 \mu \mathrm{m}$ (SEM) upon increasing the $\mathrm{Mn}_{3} \mathrm{O}_{4}$ content to $0.75 \mathrm{~mol} \%$, and finally a slight decrease is observed in both $D$ values to $30.510 \mathrm{~nm}$ (XRD) and $23.670 \mu \mathrm{m}$ (SEM) with increasing the content of $\mathrm{Mn}_{3} \mathrm{O}_{4}$ to $1.00 \mathrm{~mol} \%$, the end of tested range.

Figure 4 shows the EDX analyses for the ceramic varistors with $x=0.15,0.50$ and $1.00 \mathrm{~mol} \%$ of $\mathrm{Mn}_{3} \mathrm{O}_{4}$ at the interior of $\mathrm{ZnO}$ grain as well as on the grain boundary. Within EDX detection limit, all figures show the existence of elements $\mathrm{V}, \mathrm{Mn}$ and $\mathrm{Zn}$ both at the interior of $\mathrm{ZnO}$ grain and on the grain boundary, which indicates that both $\mathrm{V}$ and $\mathrm{Mn}$ species are dissolved in $\mathrm{ZnO}$ grains and reside on their boundaries as well. This will prove their effects on the electrical parameters as will be seen in the Section 3.2.2. 

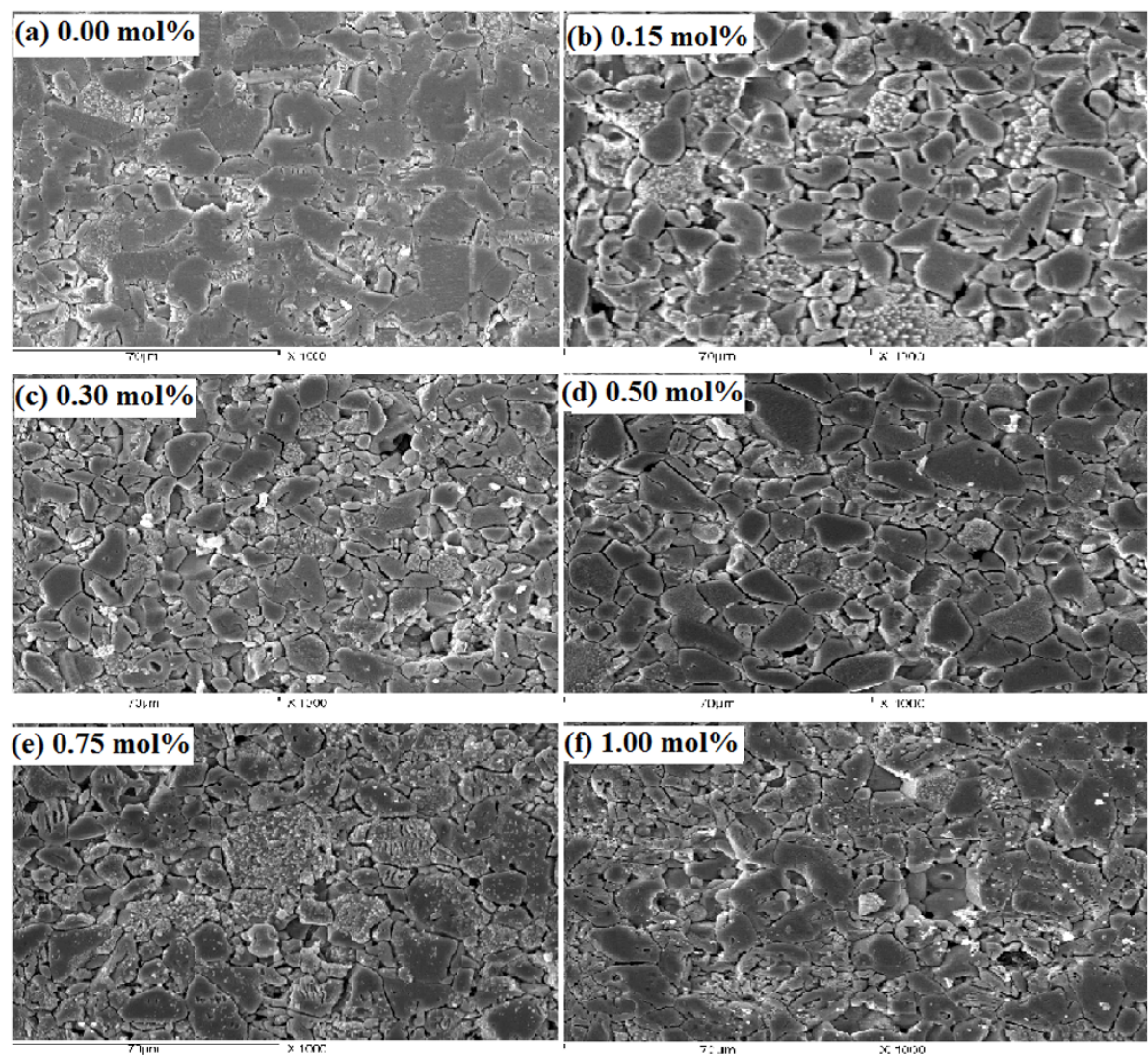

Fig. 3 SEM micrographs of $x \mathrm{Mn}_{3} \mathrm{O}_{4}-0.5 \mathrm{~V}_{2} \mathrm{O}_{5}-(99.5-x) \mathrm{ZnO}$ samples: (a) $x=0.00 \mathrm{~mol} \%$, (b) $x=0.15 \mathrm{~mol} \%$, (c) $x=0.30 \mathrm{~mol} \%$, (d) $x=0.50 \mathrm{~mol} \%$, (e) $x=0.75 \mathrm{~mol} \%$ and (f) $x=1.00 \mathrm{~mol} \%$.
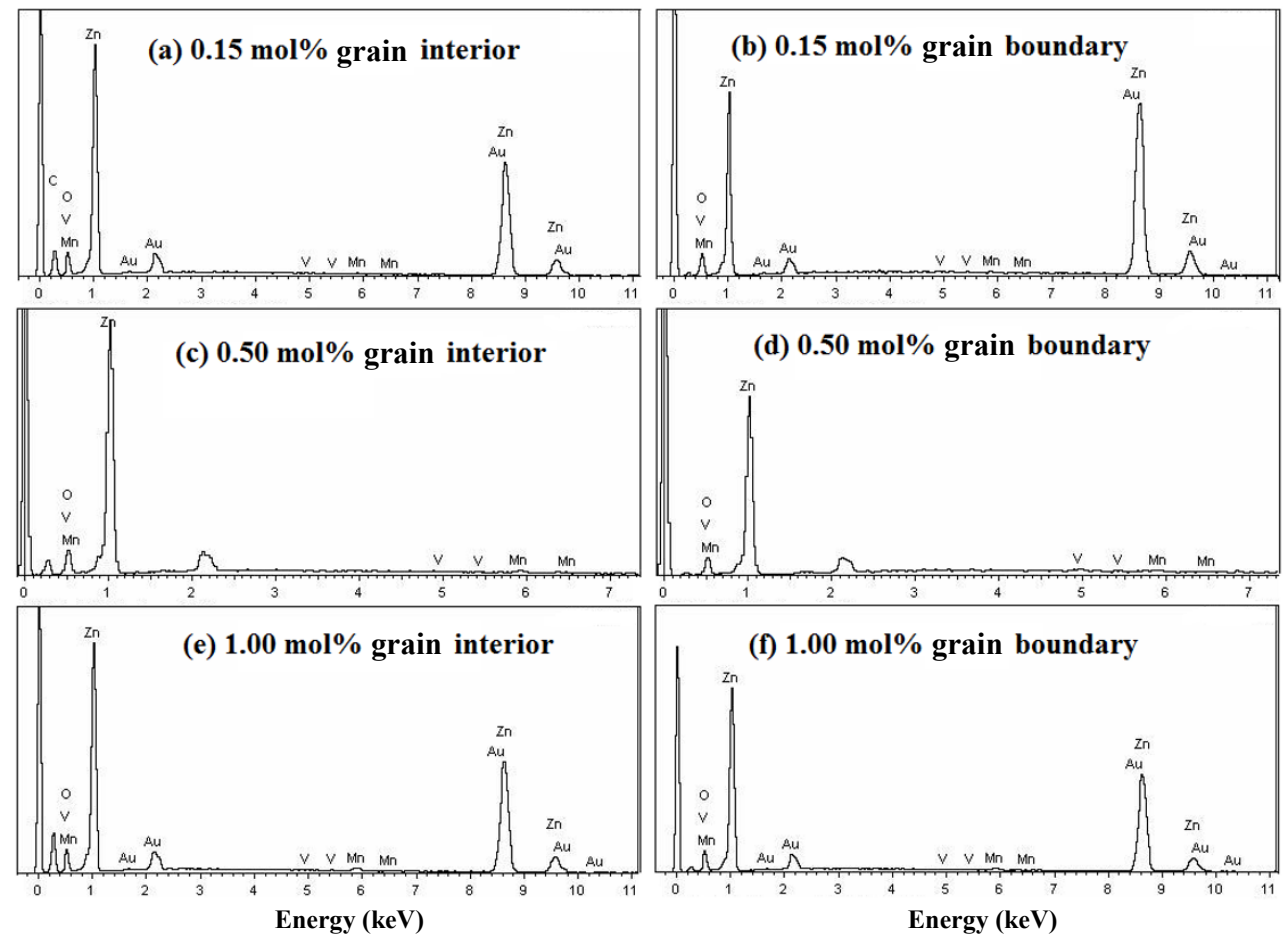

Fig. 4 EDX analyses for the ceramic varistors with $x=0.15,0.50$ and $1.00 \mathrm{~mol} \%$ of $\mathrm{Mn}_{3} \mathrm{O}_{4}$ at the interior of $\mathrm{ZnO}$ grain ((a), (c) and (e)) and on the grain boundary ((b), (d) and (f)). 
It is worth mentioning that the comparison of the compositional dependences of the grain size between EDX results observed here and those reported [17] for the same composition samples, indicates that the grain size is only consistent with those reported results in the $x$ range from 0 to $0.50 \mathrm{~mol} \%$ of $\mathrm{Mn}_{3} \mathrm{O}_{4}$ and differs beyond this content, where the previous reported results show that $D$ is nearly constant in the range from $0.5 \mathrm{~mol} \%$ to $2 \mathrm{~mol} \%$ of $\mathrm{Mn}_{3} \mathrm{O}_{4}$ [17]. On the other hand, EDX results of this work show the existence of both $\mathrm{V}$ and $\mathrm{Mn}$ elements on the boundaries as well as in the $\mathrm{ZnO}$ grain (Fig. 4), while it was reported that no $\mathrm{V}$ spiece was found in the $\mathrm{ZnO}$ grains [17]. The above differences in both results may be because the preparation of specimens (grinding methods) and sintering times in the two works are different $(5 \mathrm{~h}$ here and $3 \mathrm{~h}$ there), and only one specimen with $x=2 \mathrm{~mol} \%$ of $\mathrm{Mn}_{3} \mathrm{O}_{4}$ was presented there [17] for EDX analysis while specimens with lower contents $x=0.15,0.50$ and $1.00 \mathrm{~mol} \%$ of $\mathrm{Mn}_{3} \mathrm{O}_{4}$ are investigated in the present work.

\section{2 Electrical characterization}

\subsubsection{Current density-electric field $(J-E)$ characteristics}

Figure 5 shows the compositional dependence of the current density-electric field $(J-E)$ characteristics of $x \mathrm{Mn}_{3} \mathrm{O}_{4}-0.5 \mathrm{~V}_{2} \mathrm{O}_{5}-(99.5-x) \mathrm{ZnO}$ ceramics prepared by solid state reaction technique and sintered at $900{ }^{\circ} \mathrm{C}$ for $5 \mathrm{~h}$, where $x=0,0.15,0.30,0.50,0.75$ and $1.00 \mathrm{~mol} \%$. Inspection of Fig. 5 reveals that the varistor properties are basically characterized by non-ohmicity in all obtained $J-E$ plots and each plot is divided into two regions, an ohmic region before the breakdown and a non-ohmic one after the breakdown with some overlap between them. However, the sharper the knee of the curves between the two regions is, the better the nonlinear properties are. Also, it can be noted from Fig. 5 that the plot corresponding to the un-doped sample
( $x=0 \mathrm{~mol} \%$ of $\mathrm{Mn}_{3} \mathrm{O}_{4}$ ) shows very poor non-ohmic properties, but with increasing the $\mathrm{Mn}_{3} \mathrm{O}_{4}$ content, in other tested samples up to $0.50 \mathrm{~mol} \%$, the knee gradually becomes more pronounced and the non-ohmic properties are enhanced where the breakdown electric field $E_{\mathrm{B}}$ increases, and after the above content of $\mathrm{Mn}_{3} \mathrm{O}_{4}$, the $J-E$ characteristics show an overlap with more doping up to $1.00 \mathrm{~mol} \%$, which again results in a decrease in the breakdown field as seen in Fig. 5.

Using the $J-E$ characteristics of Fig. 5, the breakdown electric field $E_{\mathrm{B}}$, nonlinear coefficient $\alpha$, leakage current density $J_{\mathrm{L}}$, barrier height $\varphi_{\mathrm{B}}$, donor concentration $N_{\mathrm{d}}$, density of states $N_{\mathrm{s}}$, barrier width $\omega$ and non-ohmic conductivity $\sigma$ are calculated and their typical average values are summarized in Table 2 .

\subsubsection{Breakdown field and grain size}

The compositional dependences of both the breakdown field $E_{\mathrm{B}}$ and average grain size $D$ are shown in Fig. 6. From this figure, converse behaviors of changes are observed for the two parameters, as functions of the mole percentage of $\mathrm{Mn}_{3} \mathrm{O}_{4}$ content, i.e., $E_{\mathrm{B}}$ has increased and shows a peak value $(1409 \mathrm{~V} / \mathrm{cm})$ at $0.50 \mathrm{~mol} \%$ of $\mathrm{Mn}_{3} \mathrm{O}_{4}$, whereas $D$ decreases and has a

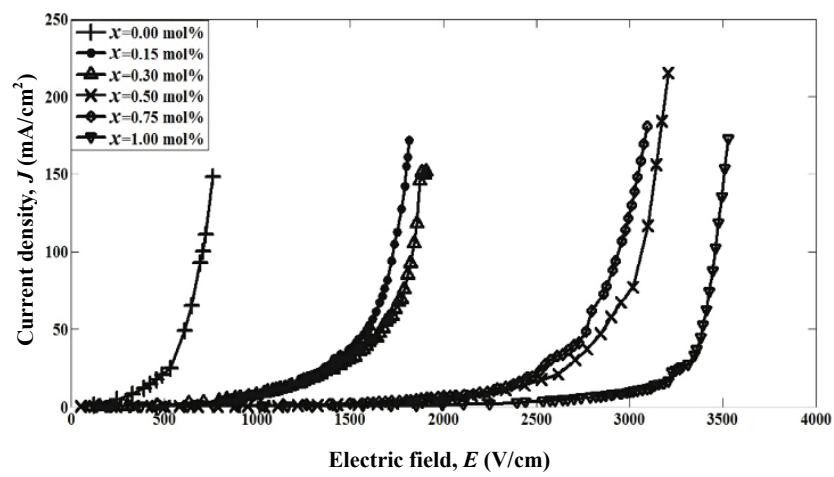

Fig. 5 Compositional dependence of $J-E$ characteristics of tested varistor ceramics $x \mathrm{Mn}_{3} \mathrm{O}_{4}-0.5 \mathrm{~V}_{2} \mathrm{O}_{5}-(99.5-x) \mathrm{ZnO}$, where $x=0,0.15$, $0.30,0.50,0.75$ and $1.00 \mathrm{~mol} \%$.

Table 2 Average calculated values of the breakdown field $E_{\mathrm{B}}$, nonlinear coefficient $\alpha$, leakage current density $J_{\mathrm{L}}$, barrier height $\varphi_{\mathrm{B}}$, donor concentration $N_{\mathrm{d}}$, density of states $N_{\mathrm{s}}$, barrier width $\omega$ and non-ohmic conductivity $\sigma$

\begin{tabular}{ccrcccccc}
\hline$x(\mathrm{~mol} \%)$ & $E_{\mathrm{B}}(\mathrm{V} / \mathrm{cm})$ & $\alpha$ & $J_{\mathrm{L}}\left(\mathrm{mA} / \mathrm{cm}^{2}\right)$ & $\varphi_{\mathrm{B}}(\mathrm{eV})$ & $N_{\mathrm{d}}\left(10^{18} \mathrm{~cm}^{-3}\right)$ & $N_{\mathrm{s}}\left(10^{12} \mathrm{~cm}^{-2}\right)$ & $\begin{array}{c}\text { Barrier width } \\
\omega(\mathrm{nm})\end{array}$ & $\begin{array}{c}\text { Non-ohmic conductivity } \\
\sigma\left(10^{-4}(\Omega \cdot \mathrm{m})^{-1}\right)\end{array}$ \\
\hline 0.00 & 118.30 & 5.33 & 0.6611 & 0.837 & 1.13 & 2.98 & 26.40 & 89.30 \\
0.15 & 229.10 & 5.63 & 0.7713 & 0.856 & 0.88 & 2.71 & 30.66 & 5.33 \\
0.30 & 493 & 11.36 & 0.6026 & 0.879 & 0.83 & 2.62 & 31.52 & 3.28 \\
0.50 & 1409 & 16.29 & 0.4419 & 0.916 & 0.77 & 2.57 & 33.47 & 0.18 \\
0.75 & 1138 & 7.62 & 0.5844 & 0.894 & 0.20 & 1.30 & 64.74 & 0.38 \\
1.00 & 1907 & 14.66 & 0.5028 & 0.909 & 0.16 & 1.18 & 72.51 & 0.09 \\
\hline
\end{tabular}




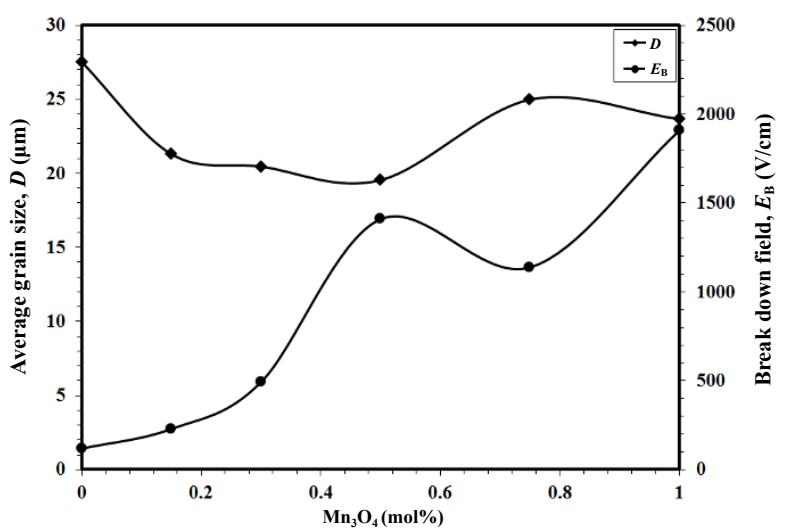

Fig. 6 Compositional dependences of both the breakdown field $E_{\mathrm{B}}$ and average grain size $D$ of $x \mathrm{Mn}_{3} \mathrm{O}_{4}-0.5 \mathrm{~V}_{2} \mathrm{O}_{5}-(99.5-x) \mathrm{ZnO}$ ceramics.

trough value $(19.545 \mu \mathrm{m})$, and vice versa is occurred at $0.75 \mathrm{~mol} \%$ of $\mathrm{Mn}_{3} \mathrm{O}_{4}$. On the other hand, on increasing the mole percentage of $\mathrm{Mn}_{3} \mathrm{O}_{4}$ beyond $0.75 \mathrm{~mol} \%$ up to $1.00 \mathrm{~mol} \%, E_{\mathrm{B}}$ increases and $D$ decreases (Tables 1 and 2). This obtained behavior of change of $E_{\mathrm{B}}$ could be interpreted based on the changes observed in the average value of grain size $D$, i.e., the initial increase of $E_{\mathrm{B}}$ with the increase of $\mathrm{Mn}_{3} \mathrm{O}_{4}$ content up to $0.50 \mathrm{~mol} \%$ is owing to the increase in the number of grain boundaries [17,26-30] which is resulted from the corresponding decrease in the average grain size and vice versa in the final part, the rest of tested range up to $1.00 \mathrm{~mol} \%$.

\subsubsection{Nonlinear coefficient and leakage current density}

Variations of the nonlinear coefficient $\alpha$ and the leakage current density $J_{\mathrm{L}}$ as functions of the mole percentage of $\mathrm{Mn}_{3} \mathrm{O}_{4}$ content of tested ceramics are shown in Fig. 7. Inspection of this figure reveals that $\alpha$ increases from 5.33 for the un-doped sample to 16.29 reaching this maximum for that which doped with $0.50 \mathrm{~mol} \%$ of $\mathrm{Mn}_{3} \mathrm{O}_{4}$, whereas further additions of $\mathrm{Mn}_{3} \mathrm{O}_{4}$ have led $\alpha$ to decrease and reach the value of 7.62 at $0.75 \mathrm{~mol} \%$ of $\mathrm{Mn}_{3} \mathrm{O}_{4}$ and then increase again to 14.66 at $1.00 \mathrm{~mol} \%$ of $\mathrm{Mn}_{3} \mathrm{O}_{4}$ content. On the other hand, $J_{\mathrm{L}}$ value decreases from $0.6611 \mathrm{~mA} / \mathrm{cm}^{2}$ with the increase of $\mathrm{Mn}_{3} \mathrm{O}_{4}$ amount from $x=0$ up to $0.50 \mathrm{~mol} \%$ reaching a minimum value, $0.4419 \mathrm{~mA} / \mathrm{cm}^{2}$ at $x=$ $0.50 \mathrm{~mol} \%$, whereas further additions of $\mathrm{Mn}_{3} \mathrm{O}_{4}$ have led $J_{\mathrm{L}}$ to increase to $0.5844 \mathrm{~mA} / \mathrm{cm}^{2}$ at $0.75 \mathrm{~mol} \%$ and decrease to $0.5028 \mathrm{~mA} / \mathrm{cm}^{2}$ at $x=1.00 \mathrm{~mol} \%$ of $\mathrm{Mn}_{3} \mathrm{O}_{4}$ content to show an opposite behavior to that observed for $\alpha$. The behaviors of both the nonlinear coefficient $\alpha$ and the leakage current density $J_{\mathrm{L}}$ mentioned above are related to the variation of the density of interface states

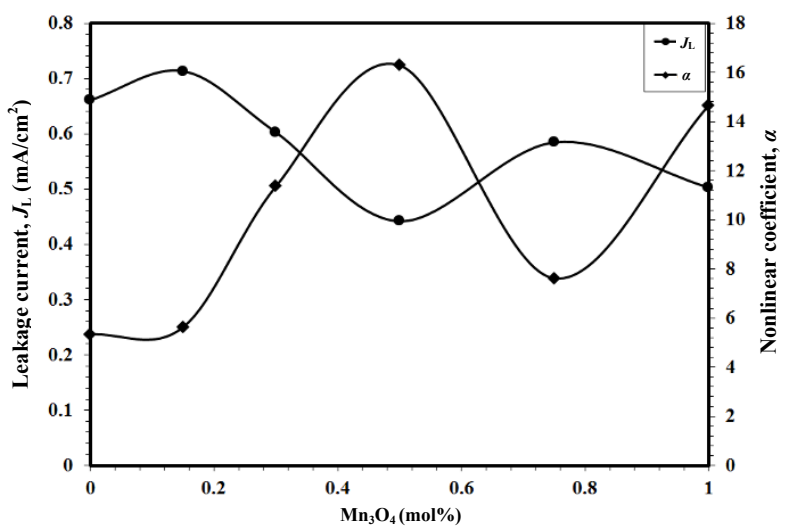

Fig. 7 Variations of average values of the nonlinear coefficient $\alpha$ and the leakage current density $J_{\mathrm{L}}$ as functions of mole percentage of $\mathrm{Mn}_{3} \mathrm{O}_{4}$ content.

$N_{\mathrm{s}}$ at the grain boundaries, and subsequently they are dependent on the Schottky barrier height $\varphi_{\mathrm{B}}$ according to the variation of the concentration of electronic donor states $N_{\mathrm{d}}$ (Table 2). It is worth mentioning that the observed value of $\alpha=16.29$ for the ceramic doped with $0.50 \mathrm{~mol} \%$ of $\mathrm{Mn}_{3} \mathrm{O}_{4}$ in this work is less than that reported for the same ceramic which was 22.4 [17]. This is perhaps due to different conditions of preparation and soaking time ( $5 \mathrm{~h}$ here and $3 \mathrm{~h}$ there) in spite of the two works were done at the same sintering temperature $900{ }^{\circ} \mathrm{C}$.

\subsubsection{Barrier height and donor concentration}

The donor concentration $N_{\mathrm{d}}$ and barrier height $\varphi_{\mathrm{B}}$ were determined by using the grain boundary defect model $[5,6]$ defined previously in the introduction part of this work as

$$
J=A T^{2} \exp \left[\left(\beta E^{1 / 2}-\varphi_{\mathrm{B}}\right) /(k T)\right]
$$

where by considering the measured current density-electric field values in the ohmic region for all samples (Fig. 5), keeping the temperature constant (at room temperature $27^{\circ} \mathrm{C}$ ) and plotting $\ln J$ versus $E^{1 / 2}$, the values of $\beta$ and $\varphi_{\mathrm{B}}$ can be derived from the obtained slopes and intersections of the extrapolated regression lines with the $\ln J$ axis, respectively. Also, since $[32,34]$

$$
\beta=\left[\left(1 /\left(r^{*} \omega\right)\right)\left(2 e^{3} /\left(4 \varepsilon_{0} \varepsilon_{\mathrm{r}}\right)\right)\right]^{1 / 2}
$$

where $r^{*}$ is the number of grains per unit length (it could be obtained from SEM micrographs (Fig. 3); $\omega$ is the barrier width; $e$ is the electron charge; $\varepsilon_{0}$ is the vacuum dielectric constant $\left(8.85 \times 10^{-14} \mathrm{~F} / \mathrm{cm}\right)$; and $\varepsilon_{\mathrm{r}}$ is the relative dielectric constant ( 8.5 for $\mathrm{ZnO})$, then $N_{\mathrm{d}}$ can be deduced from the equation [35]:

$$
\omega^{2}=\left(2 \varphi_{\mathrm{B}} \varepsilon_{0} \varepsilon_{\mathrm{r}}\right) /\left(e^{2} N_{\mathrm{d}}\right)
$$

and thus the density of states $N_{\mathrm{s}}=N_{\mathrm{d}} \cdot \omega$ [28] can also be determined and typical values for these parameters 
are listed in Table 2. The variations of both the barrier height and donor density with the mole percentage of $\mathrm{Mn}_{3} \mathrm{O}_{4}$ content in tested varistors are shown in Fig. 8 .

The illustrated figure (Fig. 8) indicates that $\varphi_{\mathrm{B}}$ increases from $0.837 \mathrm{eV}$ to $0.916 \mathrm{eV}$ by $\mathrm{Mn}_{3} \mathrm{O}_{4}$ addition up to $0.50 \mathrm{~mol} \%$, then decreases to $0.894 \mathrm{eV}$ with the gradual doping of $\mathrm{Mn}_{3} \mathrm{O}_{4}$ up to $0.75 \mathrm{~mol} \%$ and then increases to $0.909 \mathrm{eV}$ at $1.00 \mathrm{~mol} \%$ of $\mathrm{Mn}_{3} \mathrm{O}_{4}$ content. This behavior agrees with that one where it has been reported that the incorporation of $\mathrm{Mn}_{3} \mathrm{O}_{4}$ above $0.50 \mathrm{~mol} \%$ causes the electronic inactivity of grain boundaries [17]. Anyhow, the nonlinear electrical conductivity $\sigma$ shows an opposite behavior to that observed for the barrier height $\varphi_{\mathrm{B}}$ (Table 2). On the other hand, the donor density $N_{\mathrm{d}}$ shows a decrease from $1.13 \times 10^{18} \mathrm{~cm}^{-3}$ to $0.12 \times 10^{18} \mathrm{~cm}^{-3}$ with increasing of $\mathrm{Mn}_{3} \mathrm{O}_{4}$ content from 0 to $1.00 \mathrm{~mol} \%$.

\subsubsection{General discussion}

In general, the above characterizations of physical properties, density and microhardness in addition to microstructural and electrical properties of the tested $x \mathrm{Mn}_{3} \mathrm{O}_{4}-0.5 \mathrm{~V}_{2} \mathrm{O}_{5}-(99.5-x) \mathrm{ZnO}$ ceramics, $x$ changing from 0 to $1.00 \mathrm{~mol} \%$, reveal that all investigated properties are dependent on the ceramic composition rather than the secondary phases, i.e., on the mole percentage of $\mathrm{Mn}_{3} \mathrm{O}_{4}$ doping content, the different measurements obtained from employed techniques in this work show no monotonic behaviors of changes for investigated properties. Anyhow, the effect on the properties depends on the manner in which the $\mathrm{Mn}$ ions enter the $\mathrm{ZnO}$ major matrix of the hexagonal structure wurtzite phase. When $\mathrm{Mn}$ is dissolved in these $\mathrm{ZnO}$ grains, it can behave as a deep donor [13]

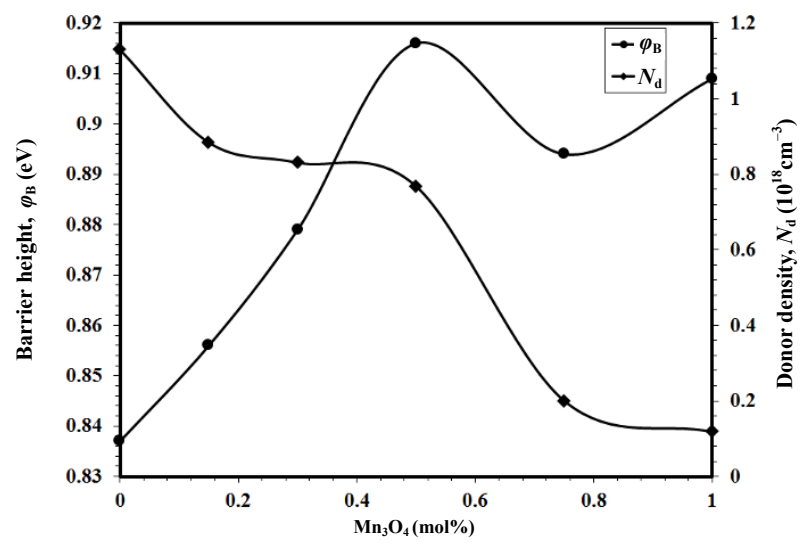

Fig. 8 Variations of the barrier height $\varphi_{\mathrm{B}}$ and the donor density $N_{\mathrm{d}}$ with the mole percentage of $\mathrm{Mn}_{3} \mathrm{O}_{4}$ content. and depress the concentrations of the intrinsic donors (oxygen vacancies). In this way, the conductivity, mainly arising from ionization of intrinsic donors, is lowered on doping up to $0.50 \mathrm{~mol} \%$ of $\mathrm{Mn}_{3} \mathrm{O}_{4}$ content. This helps to increase the nonlinear coefficient $\alpha$ and the barrier height $\varphi_{\mathrm{B}}$, and decrease the donor density $N_{\mathrm{d}}$ and the conductivity $\sigma$ (Figs. 7 and 8 and Table 2). On the other hand, with increasing Mn content through the interstitial positions, it can behave as an acceptor and has its effect to decrease the nonlinear coefficient and the height barrier $\varphi_{\mathrm{B}}$ as observed in the above mentioned figures. Also, the behavior of nonlinear coefficient $\alpha$, in accordance with the incorporation of mole percentage of $\mathrm{Mn}_{3} \mathrm{O}_{4}$, can be related to the variation of the Schottky barrier height $\varphi_{\mathrm{B}}$ according to the variation of the density of electronic states $N_{\mathrm{s}}$, the donor concentration $N_{\mathrm{d}}$ and the barrier width $\omega$ at the grain boundaries (Table 2). The doping of $\mathrm{Mn}_{3} \mathrm{O}_{4}$ into the ceramic matrix has decreased the density of interface states $N_{\mathrm{s}}$, donor concentration $N_{\mathrm{d}}$ and increased the barrier width $\omega$ as seen in Table 2. It is therefore believed that the decrease of donor concentration $N_{\mathrm{d}}$ with the increase of $\mathrm{Mn}_{3} \mathrm{O}_{4}$ content is associated with a decrease of partial pressure of oxygen in the materials [17]. The variation in $\alpha$ with further increase in $\mathrm{Mn}_{3} \mathrm{O}_{4}$ is attributed to the variation of barrier height $\varphi_{\mathrm{B}}$ as observed in Table 2 .

The ceramic microstructure has also been affected by the incorporation of $\mathrm{Mn}_{3} \mathrm{O}_{4}$ into the ceramic matrix, where obtained results show that the gradual substitution of $\mathrm{ZnO}$ by the same amount of $\mathrm{Mn}_{3} \mathrm{O}_{4}$ up to $0.50 \mathrm{~mol} \%$ has led to:

(1) Decreasing the ceramic density and the Vicker's microhardness due to the produced increase in the molar volume and the decrease in the connectivity of the microstructure as well as weak coupling between the $\mathrm{ZnO}$ grains, respectively (Fig. 1 and Table 1). These results are consistent with SEM photographs (Fig. 3) where the grains are not close together through the weak link regions, i.e., the dark region (pores) between them.

(2) Decreasing the average grain size $D$ due to the resulted increase in the number of grain boundaries and hence the breakdown electric field $E_{\mathrm{B}}$ is increased. However, further increases in $\mathrm{Mn}_{3} \mathrm{O}_{4}$ content from $0.50 \mathrm{~mol} \%$ to $0.75 \mathrm{~mol} \%$ and from $0.75 \mathrm{~mol} \%$ to $1.00 \mathrm{~mol} \%$ has increased and decreased the average grain size, respectively, to show their reverse behaviors for the obtained breakdown electric field. 


\section{Conclusions}

Microstructure, sintered density, Vicker's microhardness and electrical properties of varistor ceramics prepared by solid state reaction having compositional formula $x \mathrm{Mn}_{3} \mathrm{O}_{4}-0.5 \mathrm{~V}_{2} \mathrm{O}_{5}-(99.5-x) \mathrm{ZnO}, x=0,0.15$, $0.30,0.50,0.75$ and $1.00 \mathrm{~mol} \%$, were investigated. Both the microhardness and the sintered density of varistor samples have decreased with increasing the $\mathrm{Mn}_{3} \mathrm{O}_{4}$ content. XRD and SEM investigations show the presence of the major $\mathrm{ZnO}$ wurtzite phase of hexagonal structure and some secondary phases, such as $\mathrm{Zn}_{3}\left(\mathrm{VO}_{4}\right)_{2}$ and $\mathrm{Mn}$-rich $\mathrm{Mn}_{3} \mathrm{O}_{4}$.

Also, the results obtained from $J-E$ show that, all electrical properties: breakdown field, nonlinear coefficient, the Schottky barrier height, barrier width, the conductivity of nonlinear region, donor concentration and density of surface states at $\mathrm{ZnO}$ grain boundaries of the samples tested are dependent on the microstructure, i.e., on the grain size of existed phases, mentioned above, which affect the breakdown field. It is worth mentioning that the $99 \mathrm{ZnO}-0.5 \mathrm{~V}_{2} \mathrm{O}_{5}$ ceramic which doped with $0.50 \mathrm{~mol} \% \mathrm{Mn}_{3} \mathrm{O}_{4}$ and sintered at $900{ }^{\circ} \mathrm{C}$ for $5 \mathrm{~h}$ has exhibited optimum value for the nonlinear coefficient (16.29), the lowest leakage current density $\left(0.4419 \mathrm{~mA} / \mathrm{cm}^{2}\right)$ and the highest potential barrier height $(0.916 \mathrm{eV})$. This shows that the above sample can be used in the manufacture of low-voltage varistors and multilayer components.

Open Access: This article is distributed under the terms of the Creative Commons Attribution License which permits any use, distribution, and reproduction in any medium, provided the original author(s) and the source are credited.

\section{References}

[1] Gupta TK. Application of zinc oxide varistors. $J$ Am Ceram Soc 1990, 73: 1817-1840.

[2] Peiteado M, Fernánde JF, Caballero AC. Processing strategies to control grain growth in $\mathrm{ZnO}$ based varistors. J Eur Ceram Soc 2005, 25: 2999-3003.

[3] Levinson LM, Philipp HR. Zinc oxide varistors-A review. Am Ceram Soc Bull 1986, 65: 639-646.

[4] Deshpande VV, Patil MM, Ravi V. Low voltage varistors based on $\mathrm{CeO}_{2}$. Ceram Int 2006, 32: 85-87.

[5] Pianaro SA, Bueno PR, Longo E, et al. A new $\mathrm{SnO}_{2}$-based varistor system. J Mater Sci Lett 1995, 14: 692-694.
[6] Dhage SR, Ravi V, Yang OB. Low voltage varistor ceramics based on $\mathrm{SnO}_{2}$. Bull Mater Sci 2007, 30: 583-586.

[7] Sedky A, Al-Sawalha A, Yassin AM. Enhancement of electrical conductivity of $\mathrm{ZnO}$ ceramic varistor by $\mathrm{Al}$ doping. Egyptian Journal of Solids 2008, 31: 205-215.

[8] Matsuoka M. Nonohmic properties of zinc oxide ceramics. Jpn J Appl Phys 1971, 10: 736.

[9] Glot AB. A model of non-ohmic conduction in $\mathrm{ZnO}$ varistors. J Mater Sci: Mater El 2006, 17: 755-765.

[10] Inada M. Formation mechanism of nonohmic zinc oxide ceramics. Jpn J Appl Phys 1980, 19: 409.

[11] Houabes M, Bernik S, Talhi C, et al. The effects of aluminium oxide on the residual voltage of $\mathrm{ZnO}$ varistors. Ceram Int 2005, 31: 783-789.

[12] Bernik S, Daneu N. Characteristics of $\mathrm{ZnO}$-based varistor ceramics doped with $\mathrm{Al}_{2} \mathrm{O}_{3}$. J Eur Ceram Soc 2007, 27: 3161-3170.

[13] Sedky A, El-Suheel E. A comparative study between the effects of magnetic and nonmagnetic dopants on the properties of $\mathrm{ZnO}$ varistors. Physics Research International 2010, 2010: 120672.

[14] Sedky A, Abu-Abdeen M, Almulhem AA. Nonlinear $I-V$ characteristics in doped $\mathrm{ZnO}$ based-ceramic varistor. Physica B 2007, 388: 266-273.

[15] Sawalha A, Abu-Abdeen M, Sedky A. Electrical conductivity study in pure and doped $\mathrm{ZnO}$ ceramic system. Physica B 2009, 404: 1316-1320.

[16] Gupta TK. Microstructural engineering through donor and acceptor doping in the grain and grain boundary of a polycrystalline semiconducting ceramics. J Mater Res 1992, 7: 3280-3295.

[17] Nahm CW. Improvement of electrical properties of $\mathrm{V}_{2} \mathrm{O}_{5}$ modified $\mathrm{ZnO}$ ceramics by Mn-doping for varistor applications. J Mater Sci: Mater El 2008, 19: 1023-1029.

[18] Nahm C-W. The nonlinear properties and stability of $\mathrm{ZnO}-\mathrm{Pr}_{6} \mathrm{O}_{11}-\mathrm{CoO}-\mathrm{Cr}_{2} \mathrm{O}_{3}-\mathrm{Er}_{2} \mathrm{O}_{3}$ ceramic varistors. Mater Lett 2001, 47: 182-187.

[19] Nahm C-W. $\mathrm{ZnO}-\mathrm{Pr}_{6} \mathrm{O}_{11}-\mathrm{CoO}-\mathrm{Cr}_{2} \mathrm{O}_{3}-\mathrm{Er}_{2} \mathrm{O}_{3}$-based ceramic varistors with high stability of nonlinear properties. J Mater Sci Lett 2002, 21: 201-204.

[20] Tsai JK, Wu TB. Non-ohmic characteristics of ZnO- $\mathrm{V}_{2} \mathrm{O}_{5}$ ceramics. $J$ Appl Phys 1994, 76: 4817.

[21] Tsai J-K, Wu T-B. Microstructure and nonohmic properties of binary $\mathrm{ZnO}-\mathrm{V}_{2} \mathrm{O}_{5}$ ceramics sintered at $900{ }^{\circ} \mathrm{C}$. Mater Lett 1996, 26: 199-203.

[22] Kuo C-T, Chen C-S, Lin I-N. Microstructure and nonlinear properties of microwave-sintered $\mathrm{ZnO}-\mathrm{V}_{2} \mathrm{O}_{5}$ varistors: I, Effect of $\mathrm{V}_{2} \mathrm{O}_{5}$ doping. $J \mathrm{Am}$ Ceram Soc 1998, 81: 2942-2948. 
[23] Hng HH, Knowles KM. Characterisation of $\mathrm{Zn}_{3}\left(\mathrm{VO}_{4}\right)_{2}$ phases in $\mathrm{V}_{2} \mathrm{O}_{5}$-doped $\mathrm{ZnO}$ varistors. J Eur Ceram Soc 1999, 19: 721-726.

[24] Hng HH, Halim L. Grain growth in sintered $\mathrm{ZnO}-1$ mol\% $\quad \mathrm{V}_{2} \mathrm{O}_{5}$ ceramics. Mater Lett 2003, 57: 1411-1416.

[25] Nahm C-W. Effect of Mn doping on electrical properties and accelerated ageing behaviours of ternary ZVM varistors. Bull Mater Sci 2011, 34: 1385-1391.

[26] Nahm C-W. $\mathrm{Nb}_{2} \mathrm{O}_{5}$ doping effect on electrical properties of $\mathrm{ZnO}-\mathrm{V}_{2} \mathrm{O}_{5}-\mathrm{Mn}_{3} \mathrm{O}_{4}$. Ceram Int 2012, 38: 5281-5285.

[27] Nahm C-W. Non-omic properties and impulse aging behavior of quaternary $\mathrm{ZnO}-\mathrm{V}_{2} \mathrm{O}_{5}-\mathrm{Mn}_{3} \mathrm{O}_{4}-\mathrm{Er}_{2} \mathrm{O}_{3}$ semiconducting varistors with sintering processing. Mat Sci Semicon Proc 2013, 16: 1308-1315.

[28] Nahm C-W. Characteristics of $\mathrm{ZnO}-\mathrm{V}_{2} \mathrm{O}_{5}-\mathrm{MnO}-$ $\mathrm{Nb}_{2} \mathrm{O}_{5}-\mathrm{Er}_{2} \mathrm{O}_{3}$ semiconducting varistors with sintering processing. Mat Sci Semicon Proc 2013, 16: 778-785.

[29] Nahm C-W. Effect of erbium on varistor characteristics of vanadium oxide-doped zinc oxide ceramics. J Mater Sci: Mater El 2013, 24: 27-35.

[30] Nahm C-W. Varistor characteristics of vanadmium oxide-doped zinc oxide ceramics modified with bismuth oxide. J Mater Sci: Mater El 2013, 24: 70-78.

[31] Hng HH, Chan PL. Microstructure and current-voltage characteristics of $\mathrm{ZnO}-\mathrm{V}_{2} \mathrm{O}_{5}-\mathrm{MnO}_{2}$ varistor system. Ceram Int 2004, 30: 1647-1653.

[32] Liu H-Y, Kong H, Ma X-M, et al. Microstructure and electrical properties of $\mathrm{ZnO}$-based varistors prepared by high-energy ball milling. J Mater Sci 2007, 42: 2637-2642.

[33] Wurst JC, Nelson JA. Lineal intercept technique for measuring grain size in two-phase polycrystalline ceramics. J Am Ceram Soc 1972, 55: 109-111.

[34] Senthilkumaar S, Rajendran K, Banerjee S, et al. Influence of $\mathrm{Mn}$ doping on the microstructure and optical property of ZnO. Mat Sci Semicon Proc 2008, 11: 6-12.

[35] Morris WG. Physical properties of the electrical barriers in varistors. J Vac Sci Technol 1976, 13: 926-931. 